Revista de Estudios Histórico-Jurídicos

[Sección historia del derecho chileno]

XLII (Valparaíso, Chile, 2020)

[pp. 635-657]

\title{
LA SODOMÍA EN EL DERECHO PENAL CHILENO DEL SIGLO XIX
}

[Sodomy in Chilean criminal law of the 19th century]

\author{
Marcelo Valenzuela Cáceres* \\ Universidad Católica del Maule, Talca, Chile
}

\begin{abstract}
RESUMEN
Este artículo analiza la permanencia y la cohabitación del pecado-delito de sodomía en el derecho penal vigente en Chile durante el siglo XIX. El énfasis de esta propuesta es comprender el delito de sodomía desde la dominación del imperio español (15411810) y su continuidad en el Estado liberal a través del Código Penal de 1874. En este estudio se revisará las diferentes legislaciones del derecho penal vinculadas con el delito de sodomía, la Actas de la Comisión Redactoras del Código Penal Chileno y los primeros tratados penales nacionales que se refirieron al acto contra natura.
\end{abstract}

Palabras clave

Sodomía-derecho penal-liberalismo.

\section{Abstract}

This article analyzes the permanence and cohabitation of the sin-crime of sodomy in the criminal law in force in Chile during the 19th century. The emphasis of this proposal is to understand the crime of sodomy since the domination of the Spanish Empire (1541-1810) and its continuity in the liberal state through the Criminal Code of 1874. This study will review the different criminal law laws related to the crime of sodomy, the Proceedings of the Drafting Commission of the Chilean Criminal Code and the first national criminal treaties that referred to the act against nature.

\section{Key Words}

Sodomy - criminal law - liberalism.

RECIBIDO el 9 de diciembre de 2019 y ACEPTADO el 28 de mayo de 2020

\section{INTRODUCCIÓN}

El punto central del artículo es analizar la permanencia del pecado-delito en el Estado liberal chileno durante el siglo XIX, a través de las leyes de la corona española y el Código Penal de 1874. En esta investigación, las fuentes primarias que se han revisados provienen de la tradición medieval castellana (a través de las Siete Partidas de Alfonso el Sabio y el Fuero Juzgo) y de la legislación colonial española (la Novísima Recopilación), ya que ambos marcos, en sus apartados penales, estuvieron vigentes en Chile hasta 1875. Igualmente fueron consultadas

* Doctor en Historia de la Ciencia, Universidad Autónoma de Barcelona (UAB). Dirección electrónica: marcelovalenzuelac2011@gmail.com 
las Actas Redactoras de la Comisión de 1873, el Código Penal de 1874, el Código Penal de España de 1848 y los tratados de derecho penal de algunos abogados chilenos: Alejandro Fuenzalida, Robustiano Vera y Pedro Javier Fernández.

\section{Pecado, delito y liberalismo}

El binomio pecado-delito de sodomía ha estado vigente en Chile en tres etapas históricas: la primera, desde 1541 hasta 1875 , mediante las leyes de la monarquía hispánica. La segunda, desde la promulgación del Código Penal de 1874, el cual fue reformulado legalmente el 12 de julio de 1999 por la ley No 19.617. Esta normativa modificó el artículo 365 del texto penal, cuyo original castigaba al que "se hiciere reo del delito de sodomía". La tercera, corresponde desde 1999 y hasta la actualidad, el Código Penal de Chile sanciona cualquier relación sexual entre varones, si uno de ellos es menor de dieciocho y mayor de catorce años ${ }^{1}$.

Por lo que atañe al periodo estudiado, el pecado-delito de sodomía ha sido analizado desde dos regímenes de saber: la teología (pecado) y el derecho penal (delito). En el ámbito de la teología, el pecado se considera una falta contra la razón, la verdad y la conciencia recta; es la ausencia de amor verdadero a Dios y al prójimo a causa de un apego perverso a los bienes. En ese sentido, según Santo Tomás de Aquino (1224-1274), el pecado es una palabra, un acto o un deseo que contradice la ley eterna ${ }^{2}$. Los fundamentos de la Iglesia católica señalan que la transgresión moral (realizada por una persona) es una desobediencia, una rebelión contra Dios al pretender conocer y determinar el bien y el $\mathrm{mal}^{3}$. Se define el pecado desde la perspectiva de la Iglesia católica porque era la religión oficial y predominante en el periodo analizado, legitimada legalmente por la Constitución de 1833 hasta la separación de dicha institución con el Estado a través de la Constitución de $1925^{4}$.

La segunda conceptualización que atraviesa este estudio corresponde al término de delito, este se presenta en la vida diaria como un hecho particular (robo, violación, estupro, homicidio, agresión, sodomía, etc.) al que la ley penal atribuye una pena (corolario jurídico). Por consiguiente, el delito es cualquier hecho que se encuentra vinculado a una pena por el ordenamiento jurídico ${ }^{5}$. Desde una perspectiva histórica, el delito es una transgresión a la sociedad y al Estado. En el caso del territorio chileno, primero era una transgresión a las leyes de la monarquía hispánica que gobernó Chile entre 1541-1810 (a través del gobernador

\footnotetext{
${ }^{1}$ Congreso Nacional, Historia de la ley $N^{\circ}$ 19.617. Modifica el Código Penal, el Código de Procedimiento Penal y otros cuerpos legales, en materias relativas al delito de violación (Valparaíso, 1999); Matus, Jean Pierre; Ramírez, Cecilia, Manual de derecho penal chileno. Parte especial (Valencia, Tirant lo Blanch, 2018), p. 167.

${ }^{2}$ Aquino, San Tomás de, Summa Teologica (Madrid, Biblioteca de Autores Cristianos, 1994), I-II cuestiones, 71 a 76, pp. 550-561.

${ }^{3}$ Ibíd.

${ }^{4}$ Constitución Política de la República de Chile, promulgada el 18 de septiembre de 1925 (Santiago, Imprenta Universitaria), art. 10, inc. $2^{\circ}$, p. 9.

${ }^{5}$ Matus, Jean Pierre; Politoff, Sergio; Ramírez, Cecilia, Lecciones de derecho penal chileno. Parte general (Santiago, Editorial Jurídica de Chile, 2004), pp. 157-158; FerrajOLI, Luigi, El paradigma garantista. Filosofia critica del derecho penal (Madrid, Editorial Trotta, 2018), p. 83.
} 
y la Real Audiencia). Después del fin del dominio español en Chile, el delito fue considerado un daño a las leyes del país, siendo el Poder Judicial, desde la Constitución de 1823 y reafirmado en la Constitución de $1833^{6}$, la institución que tiene la potestad de perseguirlo. Según el artículo primero del Código Penal chileno de 1874, inspirado por su análogo español de 1848-1850, "es delito toda acción u omisión voluntaria penada por la ley" . Por consiguiente, el delito según el liberalismo penal chileno será un producto de una fuente formal del derecho y que emanará de las instituciones específicas del Estado de Derecho.

En consecuencia, la definición de delito estaba supeditada al pensamiento hegemónico del siglo XIX: el liberalismo. Esta corriente histórica se manifiesta a fines del siglo XVII y principios del siglo XVIII. La primera tradición liberal provenía de la doctrina política de los whigs ingleses ligada a la libertad de los individuos y a un Estado de derecho. La tradición whigs aportó el modelo de las instituciones políticas que se desarrolló durante el siglo XIX ${ }^{8}$. La segunda tradición liberal proviene de la filosofía ilustrada, de la escuela escocesa y de la Revolución francesa. Según este enfoque, se exigía una actitud mental de emancipación de todo prejuicio y creencia que no se pudiera justificar racionalmente, y una desvinculación de la autoridad de sacerdotes, reyes y emperadores ${ }^{9}$. Immanuel Kant (1724-1804) resume esta vertiente liberal con la frase: “'Sapere aude! ;Ten el valor de servirte de tu propia razón!'”o.

Las dos tradiciones del liberalismo coincidían con ciertos postulados esenciales: la libertad de pensamiento y la igualdad de todos los ciudadanos ${ }^{11}$. Algunas de las expresiones históricas de este planteamiento político en diferentes intensidades fueron: el proceso de independencia de Estados Unidos y de Latinoamérica, la I República francesa y la I República española.

${ }^{6}$ Constitución de la República de Chile, jurada y promulgada el 25 de mayo de 1833 (Santiago, Imprenta la Opinión), Capítulo VIII. De la Administración de la justicia, p. 34, Constitución Politica del Estado de Chile promulgada el 23 de diciembre de 1823 (Santiago de Chile, Imprenta Nacional), pp. 39-51; Constitución Política de la República de Chile promulgada el 8 de agosto de 1828 (Santiago de Chile, Imprenta de R. Rengifo).

${ }^{7}$ Código Penal de España (ed. reformada, Madrid, Imprenta Nacional, 1850), art. uno, p. 7; Código Penal de la República de Chile (Santiago de Chile, Imprenta de la República, Jacinto Núñez editor, 1874).

${ }^{8}$ HaYeK, Friedrich, Liberalismo, en Revista Ciencia Política, 4/2 (1982), pp. 122-145. Arranz, Luis, Liberalismo, democracia y revolución en Europa (1830-1939). Los casos de Francia, Italia, Alemania y Reino Unido, en GARCía, Marcela; DEL Rey, Fernando (ed.), Los desafios de la libertad. Transformación y crisis del liberalismo en Europa y América Latina (Madrid, Biblioteca Nueva, 2008), pp. 25-26; Matuccelli, Nicola, Liberalismo, en BobBio, Norberto; MatTucCelli, Nicola, Diccionario de política (México, Siglo XXI Editores, 1982), pp. 905-931.

${ }^{9}$ Foucault, Michel, ¿Qué es la Ilustración?, en Daimon Revista Internacional de Filosofia, 7 (1993), pp. 5-18; CHARTIER, Roger, Espacio público, critica y desmoralización en el siglo XVIII. Los origenes culturales de la Revolución Francesa (Barcelona, Gedisa, 1995); GolinsKY, J.V., Science in the Enlightenment, en History Science, 24 (1986), pp. 411-424; HankIns, Thomas, Ciencia e ilustración (Madrid, Siglo XXI Editores, 1988), pp. 196-198; MunCK, Thomas, Historia social de la Ilustración (Barcelona, Crítica, 2001).

${ }^{10} \mathrm{KanT}$, Immanuel, ¿Qué es la Ilustración?, en Filosofía de la historia (México, Fondo de Cultura Económica, 1994).

${ }^{11}$ HAYEK, Friedrich, Liberalismo, cit. (n. 8), pp. 123-124 
Este liberalismo político, tiene su expresión en el ámbito de la justicia y el derecho penal decimonónico. La codificación penal chilena se nutre de las ideas de los filósofos y penalistas ilustrados de los siglos XVIII y XIX: Jeremy Bentham(1738-1832), Cesare Bonesana-marqués de Beccaria (1738-1794), barón de Montesquieu (1689- 1755), Jean Jacques Rousseau (1712-1778), François Marie Arouet-Voltaire( 1694-1778), Manuel de Lardizábal (1739-1820), entre otros $^{12}$. En este sentido, siguiendo a Luigi Ferrajoli, los principios sobre los que se fundamenta el modelo de derecho penal liberal es la estricta legalidad, la materialidad y lesividad de los delitos, la responsabilidad personal, el juicio oral y contradictorio entre las partes y la presunción de inocencia. Los resultados de esta tradición filosófica del siglo XVIII y que perdura hasta hoy en los regímenes políticos son diversos: las doctrinas de los derechos naturales, las teorías contractualistas, los postulados racionalistas y empiristas, la separación de los poderes del Estado, la supremacía de la ley sobre cualquier institución y las concepciones utilitaristas del derecho y de la pena ${ }^{13}$.

En este paisaje ideológico, la élite nacional organizó el naciente Estado chileno a través de un liberalismo jurídico que se expresó en la carta magna promulgada el 25 de mayo de 1833. Esta señalaba la composición y la división de los tres poderes del Estado: el ejecutivo (presidente de la República y sus ministros), el Legislativo (Congreso Nacional bicameral) y el Judicial (Corte Suprema, cortes de apelaciones y juzgados de letras). Además, se añadieron las elecciones periódicas de algunos cargos de representación (presidente, diputado y senador) ${ }^{14}$.

A pesar de los principios liberales que aparecen en la Constitución de 1833, la política estaba restringida para los ciudadanos chilenos porque el sufragio sólo estaba permitido a los varones propietarios (voto censitario), existía una fuerte concentración de poder del presidente de la República, se consagró la religión Católica Apostólica y Romana como la oficial del país y se consolidó un régimen de administración extremadamente centralista en el cual todas las decisiones emanaban del Poder Ejecutivo ${ }^{15}$.

La continuidad del pecado-delito de sodomía paradójicamente se formalizó en un periodo de ampliación del régimen político a través del gobierno de la fusión liberal- conservadora encabezado por el presidente de la República Federico Errazuriz Zañartu (1871-1876), quien finalmente promulgó el Código Penal en 1874. Al unísono, durante la administración de Errazuriz se efectuaron una serie de reformas a la Constitución de 1833, tales como: el reconocimiento explícito de ciertas libertades (reunión, asociación y enseñanza), la prohibición de la reelección presidencial, la disminución de las atribuciones de la Comisión Conservadora y

${ }^{12}$ Prieto, Luis (2001). Capitulo VIII: La filosofía penal de la ilustración, en DE Asís RoIG, Rafael; PeCes-BARba, Gregorio; FernÁndez, Eusebio (dir.), Historia de los derechos fundamentales. Tomo II: Siglo XVIII, volumen II: La filosofia de los derechos humanos (Madrid, Editorial Dykinson S.L., 2001), pp. 127-243.

${ }^{13}$ Ferrajoli, Luigi, cit. (n. 5), p. 68

${ }^{14}$ Constitución de 1833, cit. (n. 6), p. 10.

${ }^{15}$ Collier, Simón; Sater, William, Historia de Chile 1808-1994 (Madrid, Cambridge University Press, 1999), pp. 51-63. 
del Consejo de Estado y la restricción de las facultades presidenciales en materia de estados de excepción ${ }^{16}$.

\section{El derecho penal del Chile republicano (1818-1870): tradición y cambio}

En el ámbito del derecho penal el Estado republicano chileno después del triunfo sobre la monarquía hispánica en la batalla de Maipú el 5 de abril de 1818, comenzó a dictar una serie de leyes que combinaban, ampliaban o derogaban la legislación heredada. Un ejemplo de combinación fueron aproximadamente las más de cuarenta leyes penales que se promulgaron en Chile de forma inconexa durante el periodo anterior a la codificación $(1810-1875)^{17}$. Durante aquel tiempo, el Estado republicano empezó a construir su legitimidad con nuevas disposiciones legales que emanaban del jefe de Estado, el Congreso Nacional y además de mantener algunas leyes del periodo colonial.

El gobierno del director supremo, Bernardo O'Higgins Riquelme (18171823), dictó un senado consulto el 7 de junio de 1820, donde se precisaba un orden de prelación de la legislación española para su aplicación en Chile: Recopilación de las Leyes de Indias (1680), la Novísima Recopilación (1805), el Fuero Real (1255), con su agregado de Leyes de Estilo (XIII-XVI), el Fuero Juzgo (654-681) y las Siete Partidas (1254-1265) ${ }^{18}$. Estos corpus penales fueron utilizados oficialmente en Chile para el delito de sodomía hasta la entrada en vigencia del texto penal el uno de marzo de $1875^{19}$.

El Chile del siglo XIX inició la tarea de codificación de su legislación con las constituciones políticas de 1818, 1822, 1823, 1828 y $1833^{20}$. Posteriormente, les sucedieron el Código Civil, redactado por el jurista Andrés Bello López (17811865) que entró en vigencia el uno de enero de 1857, el Código de Comercio, escrito por el argentino José Gabriel Ocampo (1798-1882) que entró en vigencia el uno de enero 1867. Por último, los códigos de minería y penal ambos de 1874 y que entraron en vigor el uno de marzo de $1875^{21}$.

Respecto a la codificación penal en Chile, fueron varios los intentos de proyec-

\footnotetext{
${ }^{16}$ Navarro, Enrique, Reformas a la Constitución chilena, en Revista de Derecho Público, Número especial (2014), pp. 13-23, esp. 14-15; ETCHEPARE, Jaime, Surgimiento y evolución de los partidos politicos en Chile 1857-2003 (Concepción, Universidad Católica de la Santísima Concepción, 2006), pp. 27-28.

${ }^{17}$ FuENSALIDA, Alejandro, Concordancia i comentario del Código Penal chileno (Lima, Imprenta Comercial, 1883), I, pp. VIII-IX. (El apellido del autor aparece con $S$ en dicha edición, su nombre correcto era Alejandro Fuenzalida Fuenzalida).

${ }^{18}$ Matus, Jean Pierre, La doctrina penal de la (fallida) recodificación chilena del Siglo XX $y$ principios del XXI, en Politica Criminal, 5/9 (Julio 2010), Art. 4, p. 144, en http://www. politicacriminal.cl/Vol_05/n_09/Vol5N9A4.pdf [visitado el 05-03.2018]; DE RrvaCOBA, Manuel, Evolución histórica del derecho penal Chileno (Valparaíso, Edeval, 1999), pp. 27-28.

${ }^{19}$ Fuensalida, Concordancias, cit. (n. 17), pp. VIII-IX; NovOA, Eduardo, Curso de derecho penal chileno (Santiago, Editorial Jurídica Ediar-Conosur, 1985), I, pp. 103-104.

${ }^{20}$ Salazar, Gabriel, Construcción de Estado en Chile (1800-1837). Democracia de los "pueblos". Militarismo ciudadano. Golpismo oligárquico (Santiago, Editorial Sudamericana, 2011).

${ }^{21}$ Campos Harriet, Fernando, Historia constitucional de Chile (Santiago, Editorial Jurídica de Chile, 2005), pp. 398-399.
} 
tos, comisiones y encargos en los años de 1822, 1826, 1831, 1840, 1846 y $1852^{22}$. Finalmente, fue una comisión redactora nombrada por el presidente José Joaquín Pérez (1861-1871) y que inicio sus trabajos en 1870, la que logró su cometido durante el gobierno de Federico Errázuriz Zañartu en $1873 .^{23}$

Los integrantes de la comisión redactora del código eran varones de la capital ligados a los partidos de la coalición gobernante, abogados, académicos de la Universidad de Chile, ex ministros de estado, diputados, jueces y ministros del Poder Judicial. La comisión estuvo presidida por Alejandro Reyes (1825-1884), de profesión abogado, integrante del Partido Nacional, siendo nombrado en 1868 ministro de la Corte de Apelaciones de Santiago. En 1870 fue electo senador por la provincia de Curicó y ese mismo año fue nombrado ministro de la Corte Suprema de Justicia ${ }^{24}$. Como secretarios participaron Julio Urriola (1846-1904), Robustiano Vera (1844-1916) y Osvaldo Rengifo Vial.

Entre los otros integrantes de la comisión encontramos a Eulogio Altamirano (1835-1905), abogado, militante del Partido Conservador y ministro del Interior en todo el periodo del presidente Errázuriz ${ }^{25}$. También, estuvo José Clemente Fabres (1826-1908) abogado, militante del Partido Conservador, profesor de la Universidad de Chile, uno de los fundadores de la Pontificia Universidad Católica de Chile y juez en la Serena y Talca. Cabe señalar que Fabres fue uno de los juristas más importantes en el ámbito del derecho civil en esta época ${ }^{26}$. Se encontraban también en la comisión José Antonio Gandarillas Luco (1839-1913), abogado, miembro del Partido Liberal-Doctrinario, ministro suplente de la Corte de Apelaciones de Santiago, desde 1872 a $1875^{27}$. Igualmente, estuvo Manuel Rengifo Vial (n. 1830) abogado, diputado por Curicó 1864-1867, quien participó en el Congreso Constituyente de 1870; fue reelecto diputado propietario por Santiago en los períodos $1870-1873$ y $1873-1876^{28}$ y hermano de uno de los secretarios de la comisión. Diego Armstrong Gana, también integró la comisión, fue diputado suplente por Llanquihue y Osorno entre 1870 a 1873.

José Vicente Ábalos (1825-1892), abogado, juez del crimen de Santiago desde el 23 de octubre de 1855 hasta $1875^{29}$, sólo estuvo un par de meses en la comisión y fue reemplazado por Adolfo Ibáñez Gutiérrez (1827-1898). Ibáñez fue ministro de Relaciones Exteriores entre el 23 de diciembre de 1871 y el 3 de enero de 1873,

${ }^{22}$ JiméneZ DE AsÚA, Luis, Códigos penales iberoamericanos según los textos oficiales (Caracas, Editorial Andrés Bello, 1944), pp. 16-17.

${ }^{23}$ De Rivacoba, Manuel, cit. (n. 18), p. 23.

${ }^{24}$ Bravo Lira, Bernardino, Anales de la judicatura chilena (Santiago, Andros Impresores, 2011), II, pp. 1150-1153.

${ }^{25}$ Matus, Jean Pierre, Legislación penal vigente en Chile (Santiago, Legal Publishing ChileThomson Reuters, 2012), p. 36; Jofré, Luis, Don Eulogio Altamirano, en Revista Chilena de Historia y Geografia, 68 (1930), pp. 73-76.

${ }^{26}$ Bravo Lira, Bernardino, cit. (n. 24), II, pp. 623-626.

${ }^{27}$ Ibíd., pp. 684-685.

${ }^{28}$ Matus, Jean Pierre cit. (n. 25), pp. 36-37.

${ }^{29}$ Bravo LiRA, Bernardino, cit. (n. 24), II, p. 247. 
reasumiendo la cartera el 14 de febrero de 1873 hasta el 3 de abril de 1875 . El 20 de octubre de 1875 asumió como fiscal de la Corte de Apelaciones de Santiago ${ }^{30}$.

El decreto que constituyó a la comisión codificadora instruyó que se tomase el Código Belga de 1867 de modelo para la redacción del texto nacional, sin embargo, los comisionados se ciñeron fundamentalmente al Código Penal de España de 1848. La comisión argumentó, que sustentar la redacción de la nueva legislación con el texto español en detrimento del belga, aseguraba una concordancia con la tradición penalista de Chile ${ }^{31}$.

El proyecto del Código Penal redactado por la comisión fue discutido en el Congreso Nacional entre 1873 y $1874^{32}$. Se dictó la ley aprobatoria el 12 de noviembre de 1874 y entró en vigencia el 1 de marzo de $1875^{33}$. Las ideas y doctrinas que contribuyeron al proceso de codificación penal chileno provenían de los filósofos de la Ilustración (que hemos señalado): Beccaria, Rousseau, Montesquieu, Voltaire entre otros. Además, de los autores de la Escuela Neoclásica, corriente del derecho penal que predominó en Alemania, Francia, Italia, España y Chile durante el periodo decimonónico. En esa línea se destacan las ideas de Pellegrino Rossi (1787-1848) quien armonizó las teorías absolutas de Immanuel Kant (1724-1804) y Georg Wilhelm Friedrich Hegel (1770-1831) y el utilitarismo de Jeremy Bentham ${ }^{34}$.

El texto chileno se encuadra en la gran familia de códigos derivados de su homólogo francés de 1810. Siendo sus principales modelos el código español de 1848 y el código belga de 1867. La codificación penal chilena fue una refundición del texto español como se observa en la dimensión ideológica y técnica e incluso en la rutina de las escalas y en las tablas demostrativas de las penas. Además, el nuevo texto pena adoptó la tripartición francesa de infracciones, vigente también en el código español. ${ }^{35}$

\footnotetext{
${ }^{30}$ Rojas, Ximena, Don Adolfo Ibáñez. Su gestión con el Perú y Bolivia 1870-1879 (Santiago, Editorial Andrés Bello, 1970), pp. 11-19.

${ }^{31}$ Novoa, Eduardo, cit. (n. 17), p. 105; Cury, Enrique, Derecho penal. Parte general (Santiago, Editorial Jurídica de Chile, 1982), I, p. 116; Eyzaguirre, Jaime, Historia del derecho (Santiago, Editorial Universitaria), pp. 211-212.

${ }^{32}$ Etcheberry, Alfredo, Derecho penal, parte general (Santiago, Editorial jurídica de Chile, 1997), I, pp. 45-47; GuZMÁn, José Luis, Reseña histórica de la codificación y procesal penal en Chile, en La ciencia penal en la Universidad de Chile, Facultad de Derecho, Universidad de Chile, Libro homenaje a los profesores de Departamento de Ciencias Penales, (Santiago, Universidad de Chile, 2013), pp. 106-107; DEL VILLAR BRITO, Waldo, Cien años de legislación penal codificada de Chile, en: DE Rivacoba, Manuel, Actas de las jornadas internacionales de derecho penal en celebración del centenario del Código penal chileno (Valparaíso, Edeval, 1975), pp. 361-365; SÁnCHEZ, Gonzalo, Manuel José Yrarrázaval Larraín una vida entregada a la patria (Santiago, Ediciones Pontificia Universidad Católica, 2005).

${ }^{33}$ Anguita Ricardo, Leyes promulgadas en Chile: desde 1810 hasta el 1 de junio de 1913 (Santiago, Imprenta Litografía i Encuadernación Barcelona, 1913), p. 352.

${ }^{34}$ Peña, Silvia, Las raíces histórico-culturales del derecho penal chileno, Revista de Estudios Histórico-Jurídicos, 7 (1982), p. 311.

${ }^{35}$ Iñesta, Isabel, El Código Penal chileno de 1874, en Revista Chilena de Historia del Derecho, 19 (2003-2004), pp. 293-328; QUINTANO, Antonio, La influencia del derecho penal español en las legislaciones hispanoamericanas (Madrid, Ediciones Cultura Hispánica, 1953), pp. 108-109.
} 
En consecuencia, la comisión que redactó el Código Penal estaba permeada por la doctrina neoclásica que se encontraba en boga en el siglo XIX. Esta modernización en la legislación fue señalada en el discurso de apertura del Congreso Nacional el primero de junio de 1873, por el presidente Errázuriz: "He dedicado una atención preferente al interesante trabajo de la codificación de las antiguas y defectuosas leyes españolas que hasta ahora nos rigen [...]. Renovar nuestras viejas instituciones, purgándolas de sus defectos y llenado sus vacíos; inocular en nuestras nuevas leyes el espíritu de progreso que ha alcanzado las sociedades modernas y afirmar y dar ensanche a los derechos y libertades del ciudadano den la más amplia latitud que sea conciliable con los elevados intereses del orden social; tales son mis más sinceras aspiraciones y tales deben ser los grandes fines de vuestras patrióticas tareas" 36 .

El primer mandatario, en su mensaje al parlamento, caracterizó la supresión de las legislaciones coloniales de una manera positiva y también las descalificó porque estas se encontraban desfasadas con la realidad de Chile en aquel momento. El discurso del presidente equiparó las reformas penales con el progreso social del país, es decir, argumentó que el propósito de un nuevo texto penal era superar lo antiguo (hispano) y consolidar lo nuevo (republicano).

El 29 de octubre de 1873 el Poder Ejecutivo envío un mensaje con el proyecto de Código Penal para su aprobación en el Congreso Nacional. Los firmantes, el presidente Federico Errázuriz Zañartu y su ministro José María Barceló (18351897) indicaron: "La legislación española, apenas modificada por leyes patrias especiales, adolecía de gravísimos defectos que hacían inaceptable por más tiempo su subsistencia. La naturaleza de algunas penas y la apreciación de diversos delitos, se resienten de las ideas dominantes en los tiempos remotos a que gran parte de esa legislación corresponde. A más de esto, las nuevas instituciones sociales y ensanche que día a día reciben, han creado y crean sin cesar derechos nuevos que la ley debe tomar bajo su amparo para que prosperen y den los frutos de progreso y de riqueza que sirven de base sólida a las sociedades modernas" ${ }^{37}$.

Las autoridades rechazaban los castigos penales que no se armonizaban con los tiempos que vivía la sociedad chilena y señalaban que la nueva legislación permitiría una concordancia con las instituciones que se estaban construyendo. El texto penal de 1874 cumplía la función de unificar la legislación penal chilena, es decir, se abandonaba el intrincado y obsoleto sistema de legislaciones fragmentadas, forales y de privilegios de estamentos.

\section{La sodomía en el Chile colonial y republicano (1541-1875)}

Como se indicó anteriormente, el pecado-delito de sodomía durante el siglo XIX ha estado vigente en Chile primero con las leyes del imperio español y luego con el Código Penal de 1874. En el año 1999 se realizaron ciertas reformas al

\footnotetext{
${ }^{36}$ Errázuriz Zañartu, Federico, Discurso de su excelencia el Presidente de la República en la apertura del Congreso Nacional de 1874 (Santiago de Chile, Imprenta Nacional, 1874), p. 7.

${ }^{37}$ Errázuriz Zañartu, Federico; Barceló, José María, Mensaje del gobierno acompañando el presente Código Penal al Congreso, 27 de octubre de 1873, en Código Penal (Santiago, Editorial Jurídica de Chile, 1984), pp. 13-18.
} 
apartado correspondiente a las contravenciones sexuales y en esa ocasión el delito de sodomía fue reformulado. El delito de sodomía continua vigente hasta hoy porque castiga la relación homosexual entre varones, en que uno de los integrantes sea menor de dieciocho años y mayor de catorce años (y que la relación no tenga circunstancias de violación o de estupro) ${ }^{38}$.

Con respecto al origen del término de sodomía, este se encuentra en el Antiguo Testamento en el libro del Génesis ${ }^{39}$. En el capítulo 19 del Génesis se relata la historia de los ángeles que visitaron la ciudad de Sodoma, donde Lot les concede hospedaje en su morada. Los ángeles cenaron y cuando estaban próximos a dormir, los varones de la ciudad rodearon la casa de Lot y les exigieron que salieran para violarlos. Frente a esa coyuntura, los ángeles le dijeron a Lot que reuniera a su familia y abandonara Sodoma porque Yahvé la destruiría ${ }^{40}$.

La interpretación de este pasaje de la Biblia, sostiene que Yahvé sancionó a los habitantes de Sodoma y Gomorra por intentar violentar sexualmente a los ángeles que él envió. Filón de Alejandría (15 a.C.-45 d.C.), teólogo judío fue el primero en imbricar la destrucción por orden divina de las dos ciudades y el sexo entre varones ${ }^{41}$. Además, de esta condena del Antiguo Testamento existen cientos de cartas, tratados, edictos, sermones y sínodos en los cuales la Iglesia católica repudia y castiga el contacto sexual entre varones ${ }^{42}$.

La condena cristiana a la sodomía en Chile entre 1541 a 1875 se cristalizó a través de las legislaciones implantadas por los conquistadores españoles, la primera corresponde al Fuero Juzgo o Liber Iudiciorum. En el territorio hispano durante la Edad Media el derecho romano nunca se impuso totalmente al derecho de los pueblos ibéricos, y fue pronto reemplazado por las disposiciones penales visigodas ${ }^{43}$. Las recopilaciones de dichas leyes culminaron en la formación del Fuero Juzgo en la época de los reyes Recesvinto (622-672) en el año 654, y luego complementado por Ervigio en el año 681. Esta legislación penal visigoda demuestra la influencia del derecho romano y del eclesiástico a través de los concilios de Toledo (377-702) ${ }^{44}$. El Fuero Juzgo rechazaba la venganza privada, admitía la gradación subjetiva en los delitos, como el homicidio, y reglamentaba, a la par que

${ }^{38}$ Para los debates de la permanencia de esta figura penal revisar: RoDRíGUEz, Luis, Delitos sexuales de conformidad con las modificaciones introducida por la ley $N^{\circ} 19.617$ de 1999 (Editorial Jurídica de Chile, Santiago, 2000), pp. 17-22, Matus, Jean Pierre; Ramírez, Cecilia, cit. (n. 1), p. 167.

${ }^{39}$ Antiguo Testamento, Génesis 19: 4-19.

${ }^{40}$ Ibíd.

${ }^{41}$ Hopman, Jan, La sodomía en la historia de la moral eclesial, en Olavarría, José; Parrini, Rodrigo, Masculinidades, identidad, sexualidad y familia, primer encuentro de estudio de la masculinidad (Ñunoa, Flacso, 2000), pp. 113-122.

${ }^{42}$ Antiguo Testamento, Levítico 18: 22, Deuteronomio 23: 17, Deuteronomio 22: 5 y Nuevo Testamento, Primera Carta a los Corintios, San Pablo; Boswell, John, Cristianismo, tolerancia socialy homosexualidad (Barcelona, Munchnik Editores S.A., 1992); AwI, Alexandre, ¿Qué dice la Biblia sobre la homosexualidad?, en Teología y Vida, 42/2 (2001), pp. 377-398.

${ }^{43}$ PeÑA, Silvia, cit. (n. 34), pp. 289-314.

${ }^{44}$ PeÑA, Silvia, cit. (n. 34), pp. 289-314. 
restringía, la tortura. El texto penal visigodo no se aplicó en toda su integridad y convivió con las legislaciones forales localistas.

Con respecto a la sodomía, en el Fuero Juzgo se ordenaba que los varones que tuvieran relaciones sexuales entre ellos fueran castrados y entregados al obispo correspondiente para que los pusiera en cárceles separadas para que hicieran penitencia. En el caso de que los condenados estuvieran casados, sus bienes se traspasarían a sus hijos legítimos y sus mujeres podrían casarse con quienes qui$\operatorname{sieran}^{45}$. Por lo tanto, en esta legislación, cuando un imputado era considerado culpable, el castigo estaba ligado a la pérdida de sus bienes materiales y de la jefatura de la familia (patria potestad).

La otra legislación que corresponde a la tradición jurídica castellana fueron las Siete Partidas de Alfonso X de Castilla (1252-1285) las cuales fueron redactadas entre 1254 a 1265 . En la séptima Partida están consignados los apartados concernientes al derecho penal y el derecho procesal penal. En dicho capítulo se encuentran definidos una variedad de figuras penales tales como: rapto, incesto, alcahuetería, estupro, sodomía, violación, bestialismo, aborto, entre otros ${ }^{46}$. La ley alfonsina señalaba que la sodomía era un pecado de lujuria y fundamentaba la definición desde la antropología cristiana: "Sodomítico dicen al pecado en que caen los homes yaciendo unos con otros contra bondat et costumbre natural. Et porque de tal pecado como este nascen muchos males á la tierra do se face, et es cosa que pesa mucho á Dios con ella, et sale ende mala fama non tan solamente á los facedores, más aun á la tierra do es consentido: por ende pues que en los titulos ante deste fablamos de los otros yerros de luxuria" [...] "Sodoma et Gomorra fueron dos cibdades antiguas que fueron pobladas de muy mala gente: et tanta fue la maldat de los homes que vivieron en ella, que porque usaban aquel pecado que es contra natura, los aborrecio nuestro señor Dios de guisa que sumio amas las cibdades con toda la gente que hi moraba, que no estorcio ende sinon solamente Lot et su compaña que no habien en si maldat" ${ }^{37}$.

Para la teología cristiana la sodomía era una ofensa a Dios y está subordinado a un pecado capital: la lujuria. Según la Iglesia católica la lujuria en su máximo grado provoca compulsiones sexuales, incluyendo la adicción a la copulación, el adulterio, la violación, la sodomía, el incesto y/o el abuso de menores ${ }^{48}$. Por lo tanto, la sodomía es una consecuencia del exceso de lujuria, porque predomina el goce sexual en vez de la reproducción de la especie entre un varón y una mujer.

La ley alfonsina explica el origen de la palabra sodomía desde la tradición judeo-cristiana. Este vocablo fue acuñado al considerar que las personas de las ciudades de Sodoma y Gomorra practicaban el coito entre varones. En consecuencia, Dios castigó a los habitantes de dichas urbes, destruyéndolas. En este apartado el énfasis que planteaba el legislador era la falta de respeto al orden natural (la práctica sexual en función de la reproducción de la especie). En consecuencia, en

${ }^{45}$ Fuero Juzgo (1815), p. 83 [1241].

${ }^{46}$ Alfonso X El SABIO, Las Siete Partidas (Madrid, Imprenta Real, 1807), III, Partida Séptima, Título XXI, pp. 664-665.

${ }^{47}$ Ibíd.

${ }^{48}$ Deschner, Karheinz, Historia sexual del cristianismo (Zaragoza, Editorial Yalde, 1993), pp. $210-227$. 
la séptima Partida se encuentran dos delitos: a) el acto sexual entre dos varones adultos, que conlleva la pena de muerte y b) la violación sexual de jóvenes menores de 14 años, en la cual la víctima no recibirá condena.

A pesar de la existencia de una legislación que perseguía a los sodomitas, aún quedaban amplios vacios legales sin regular en el ámbito penal en la monarquía hispánica y sus colonias. Por consiguiente, los Reyes Católicos Fernando de Aragón (1452-1516) e Isabel I de Castilla y León (1451-1504) decretaron el 22 de agosto de 1497 a través de una pragmática ${ }^{49}$ una nueva condena del delito nefando, precisando los procedimientos para investigarlo y los castigos para los perpetradores ${ }^{50}$.

En el año 1568, el rey Felipe II (1556-1598) publicó la pragmática “Prueba privilegiada del delito nefando para la imposición de su pena ordinaria. Señalando que los acusados de delito pecado nefandos, las pruebas en el proceso criminal se simplifican ${ }^{\text {} 1}$. La finalidad de esta normativa era simplificar las pruebas para acusar con mayor facilidad a los imputados de prácticas sodomíticas. Posteriormente el 27 de octubre de 1704 el rey Felipe V (1700-1724) definió la jurisdicción de la sodomía privilegiando la justicia civil en vez de la militar para sancionar a los soldados que estuvieran involucrados en dicho delito ${ }^{52}$.

Para 1805, el rey Carlos IV (1788-1808) promulgó la Novísima Recopilación de Leyes de España la que era una sistematización del derecho hispano. Este texto reforma el compendio de Felipe II, incorporando pragmáticas, decretos, órdenes y leyes locales emitidas hasta 1804 quedando dividido en doce libros. Al igual que en las Siete Partidas el último apartado se dedica al derecho penal. Particularmente, en el Título XXXI se encuentran las condenas a las prácticas sodomíticas de los diferentes monarcas españoles que fueron descritas con anterioridad ${ }^{53}$. Por lo tanto, cuando Chile era un territorio controlado por la corona española, el delito de sodomía era sancionado por todas las legislaciones anteriormente nombradas.

\section{El pecado-delito de sodomía en las Actas de la Comisión Redactora del Código Penal chileno (1870-1873)}

La comisión encargada de redactar el Código Penal comenzó a sesionar el 8 de marzo de 1870 y en su labor se guiaron, según hemos señalado, por los textos penales de España de 1848 y de Bélgica de 1867. Estos corpus legislativos no contaban con ningún artículo relacionado con la sodomía, a diferencia de los correspondientes textos del Ancién Régime. A pesar de eso, los redactores chilenos decidieron conservar el delito de sodomía porque según ellos se debía evitar "su contagio y llegue a ser una plaga en la sociedad"s4. El tópico sobre las prácticas

${ }^{49}$ Leyes del Antiguo Régimen español que se emitían para remediar algún abuso.

${ }^{50}$ Novísima Recopilación de las Leyes de España, libros X, XI y XII (Madrid, 1805), Libro XII, De los delitos, y sus penas, y de los juicios criminales. Título XXX, De la sodomía, y bestialidad, pp. $427-429$.

${ }^{51}$ Ibíd., pp. 428-429.

${ }^{52}$ Ibíd.,

${ }^{53}$ Ibíd., p. 430.

${ }^{54}$ Actas de las sesiones de la Comisión Redactora del Código Penal Chileno (Santiago, Imprenta 
sodomíticas fue discutido en la comisión redactora en sus sesiones 71 y 72 del 10 y 17 de abril de 1872: "Discutido el párrafo 40. Que castigaba 'el estupro y la corrupción de menores', se acordó modificar su epígrafe diciendo: 'Del estupro, incesto, sodomía, de otros delitos deshonestos y de la corrupción de menores', en atención a que el concúbito de parientes dentro del grado prohibido tiene el nombre especial de incesto, y que convenía incluir en este párrafo, por su analogía con las otras materias de que trata, los abusos deshonestos y la sodomía, no mencionados en el proyecto original" 55 .

La finalidad de preservar el delito de sodomía en el Código Penal era para diferenciarlo de otras sanciones que hacían referencia a las prácticas sexuales entre varones y mujeres (estupro, incesto, violación y abusos deshonestos). Además, a través del delito de sodomía se sintetizaba a todas las prácticas sexuales ilícitas realizadas entre varones y que eran castigadas.

En definitiva, el artículo sobre el delito de sodomía era una coerción moral con fuerza legal en contra de este hecho delictivo en el territorio nacional. En el ámbito de la pena los comisionados señalaron lo siguiente: "Dos nuevos artículos, para castigar en el primero el delito de sodomía con la pena de presidio menor en cualquiera de sus grados y multa, y en el otro los actos deshonestos con persona de uno u otro sexo que no estén comprendido en los artículos anteriores, designándose la misma pena que en el primero" ${ }^{56}$.

El delito de sodomía estaba tipificado a través de una tecnificación liberal: un articulado único y una pena moderada. El acusado de prácticas sodomíticas en esta futura legislación no era sancionado con el afán de exhibición y degradación corporal que el Ancién Régime propugnaba en sus penas ${ }^{57}$ sino que, este cumpliría tres años de presidio en una cárcel. ${ }^{58}$

El artículo 352 de las actas de la comisión redactora (posteriormente, en la discusión del Congreso Nacional la numeración sería modificada) señalaba: " $e l$ que se hiciere reo del delito de sodomía, sufrirá la pena (de) presidio menor en cualquiera de sus grados y multa"59. El propósito del artículo era sancionar cualquier práctica sexual entre varones, convirtiéndose en un notorio influjo de la moral católica porque los redactores de texto penal estaban castigando el acto de "yacer omes con omes ${ }^{\prime 60}$, sin diferenciar la edad, el consentimiento y/o el acceso carnal con violencia ${ }^{61}$.

de la República de Jacinto Núñez, 1873), pp. 139-142.

${ }^{55}$ Ibíd., p. 138.

${ }^{56}$ Ibíd., pp. 139-140.

${ }^{57}$ Foucault, Michel, Vigilar y castigar. Nacimiento de la prisión (México, Siglo XXI Editores, 1999), pp. 18-19.

${ }^{58}$ INESTA, Emilia, Antecedentes históricos-jurídicos del código penal chileno de 1874, en DE LA Puente Brunke, José; Guevara Gil, Jorge Armando, XIV congreso del Instituto Internacional de Historia del Derecho Indiano, Derecho, instituciones y procesos históricos (Perú, Instituto RivaAgüero de la Pontificia Universidad Católica del Perú, 2008), III, pp. 240-241.

${ }^{59}$ Actas de las sesiones, cit. (n. 54), p. 140.

${ }^{60}$ Novisima Recopilación, cit. (n. 50), V; Siete Partidas, cit. (n. 46), III.

${ }^{61}$ Rojas Araya, Joel, El castigo de la sodomía y la libertad sexual en Chile, en Anuario de la Facultad de Ciencias Jurídicas, Sección I (2001), p. 154. 
En la misma sesión después de consignar a la sodomía en el futuro texto penal, los comisionados discutieron la utilidad del delito de bestialidad: "Se suscitó dudas sobre si debía o no penarse el delito de bestialidad, y el señor Ibáñez manifestó que en su concepto convenía no tomarlo en cuenta en el presente código, tanto por la rareza de su perpetración, cuando no hay peligro de que se extienda su contagio y llegue a ser una plaga para la sociedad como sucedía con la sodomía"62.

Según Adolfo Ibáñez el delito de bestialidad era escasamente practicado a diferencia de la sodomía que se realizaba con mayor frecuencia. Ibáñez señaló que la sodomía era una peste contagiosa que podría convertirse en una plaga que afectaría a toda la sociedad y abogaba por la conservación del castigo en el futuro texto penal. Finalmente, el delito de bestialidad fue omitido del texto penal.

En la sesión 72 del 17 de abril de 1872 se debía aprobar el acta anterior. Sin embargo uno de los integrantes, José Clemente Fabres (1826-1908), votó en contra de dicha acta porque se castigaba a los sacerdotes: "Se puso en discutido el párrafo 7; que contiene varias disposiciones a los sacerdotes, tanto porque no cree que la autoridad civil pueda imponerles pena, como lo ha observado en otras ocasiones, cuanto porque en el caso actual el castigo solo tendría por resultado el desprestigio inmediato del sacerdocio, al cual no puede imputarse faltas como las que el artículo pena"63.

La opinión del comisionado en el párrafo anterior hacía alusión a los delitos sexuales de corrupción de menores, estupro, abuso deshonesto y sodomía. El objetivo de esta enmienda era proteger a los eclesiásticos en detrimento de la igualdad ante la ley y a la protección de las víctimas. Fabres siempre estuvo ligado a los sectores más conservadores de la sociedad chilena, entre 1883 y 1884 se opuso a las leyes de laicización (cementerios laicos, matrimonio civil y Registro Civil) ${ }^{64}$ y además fue uno de los fundadores de la Pontificia Universidad Católica de Chile en $1888^{65}$. El jurista intentó (a través de su enmienda) salvaguardar el prestigio de la Iglesia y el clero, pero en la práctica su propuesta era privilegiar a un estamento específico en una legislación penal liberal. La moción para evitar el castigo penal a los sacerdotes católicos que estuvieran involucrados en prácticas sodomíticas fue rechazada por la comisión redactora.

La continuidad de la sodomía en la legislación penal, representa una evidente tensión entre la tradición y el cambio en el Chile decimonónico. Las elites nacionales asimilaban las novedades europeas por medio de las vestimentas, los estilos arquitectónicos, las costumbres, los discursos y el aprendizaje de la lengua francesa. No obstante a lo anterior, esta imitación de Europa era de una forma aparente, porque cualquier innovación (en este caso el código penal) fue adop-

\footnotetext{
${ }^{62}$ Actas de las sesiones, cit. (n. 54), p. 140.

${ }^{63}$ Ibíd.

${ }^{64}$ Fabres, José Clemente, Los cementerios católicos, en El Estandarte Católico, 2.878, Santiago de Chile, 16 de diciembre de 1883.

${ }^{65}$ Krebs, Ricardo; Muñoz, María Angélica; Valdivieso, Patricio, Historia de la Pontificia Universidad Católica de Chile, 1888-1988 (Santiago, Ediciones de la Universidad Católica de Chile, 1994).
} 
tada y adecuada a los intereses de las clases dominantes que manejaron el Estado chileno en el siglo XIX.

Señalamos esto dado que la Revolución francesa ya había eliminado el delito de sodomía en el código penal revolucionario redactado por la Assemblée Nationale Constituante en $1791^{66}$. Posteriormente, el cambio fue consagrado con el Codé Pènal de Napoleón Bonaparte (1769-1821), aprobado entre febrero y marzo de 1810 y que entró en vigor el uno de enero de $1811^{67}$. La sodomía tampoco se contemplaba en los códigos penales españoles de 1822 y 1848 ni en el belga de 1867. Sin embargo, sería erróneo considerar que en la Europa de los siglos XVIII y XIX el sexo entre varones era aceptado social y jurídicamente; este se continuó persiguiendo mediante otras figuras penales tales como: el vagabundaje, el atentado al pudor, el abuso deshonesto y la prostitución ${ }^{68}$.

Se entiende que el artículo de sodomía en el Código Penal chileno, fue el reflejo de un pacto de longué dureé formado por el Estado liberal y la Iglesia católica, alianza que atravesó todas las etapas de convivencia, conflicto, negociación y armonización y que, en el fondo, como lo ejemplifica este delito era una unión sólida. En esta época se resalta la laicización de la sociedad (conflicto Iglesia-Estado) a través de las nuevas legislaciones aprobadas: la Ley Orgánica de Tribunales de 1875, el Código Penal de 1874, la Ley de inhumación de cadáveres de 1883, la Ley sobre Registro Civil de 1884 y finalmente la Ley de Matrimonio Civil $1884^{69}$. No obstante a lo anterior, la antropología cristiana era compartida transversalmente por los sectores liberales y conservadores del periodo, y fue un punto de convergencia para mantener en el texto penal el delito de sodomía.

El comité de redacción del texto penal no confundió entre delito y pecado cuando redactó el artículo 352, sino que fue una construcción completamente acorde con los principios morales, éticos y culturales de sus integrantes. Posteriormente, quedo consignado en el Código Penal de 1874 el artículo 365 que señalaba "el que se hiciere reo de sodomía será condenado a la pena de un grado" 70 y dicho delito y pena quedo registrado en el Libro II, título VII "Crímenes y simples delitos

\footnotetext{
${ }^{66}$ Corral Talciani, Hernán, La privatización de la sexualidad y de la familia, en Simposio Internacional: Revisión del legado jurídico de la Revolución francesa en las Américas 28 de abril 2011 (Santiago, Universidad Bernardo O’Higgins, 2011), pp. 147-152; Código Penal de Francia de 1791, en Revista de Derecho Penal y Criminología, Tercera época, 1 (2009), pp. 481-517; PASTORRELlo, Thierry, L'abolition du crime de sodomie en 1791: un long processus social, répressif et pénal, en Cahiers d'Histoire. Revue d'Histoire Critique, 112-113 (2010), pp. 197-208.

${ }^{67}$ Martín, María, Aproximación histórica al tratamiento jurídico y social dado a la homosexualidad en Europa, en Estudios Constitucionales, 9/1 (2011), pp. 245-276; Damien, André, Code pènal, en Tulard, Jean, Dictionaire Napoleón (París, Fayard, 1987), pp. 433-434; Veillon, Didier, La rédaction du Code pénal de 1810, en Slovenian Law Review, 6/1-2 (december 2009), pp. 143-157.

${ }^{68}$ Revenin, Régis, Homosexualité et prostitution masculines á Paris 1870-1918 (Paris, L'Harmattan, 2005), pp. 166-169.

${ }^{69}$ Stuven, Ana María, La Iglesia católica chilena en el siglo XIX. Encuentros y desencuentros con la modernidad filosófica, en Teología y Vida, 56/2 (2015), pp. 187-217; MARTínEZ, Rosa María, La Iglesia católica en la América independiente (siglo XIX) (Madrid, Editorial MAPFrE, 1992).

${ }^{70}$ Código Penal de 1874, Título Séptimo, Artículo 365, p. 141.
} 
contra el orden de las familias y la moralidad pública" ${ }^{71}$. En el título del apartado en que se encuentra el delito de sodomía se señaló la lesividad que transgredía.

Por consiguiente, los redactores del código chileno enlazaron el principio de lesividad u ofensividad con dos elementos ideológicos del Chile decimonónico: el liberalismo y la moralidad católica. El principio de lesividad u ofensividad es una estructura de tipo penal indispensable para poder condenar a un individuo acusado de violentar, dañar o transgredir un bien jurídicamente tutelado por el Estado $^{72}$. Desde la perspectiva liberal del derecho penal, el principio de lesividad tiene como finalidad el proteger, a través de la fuerza coactiva del Estado, determinados bienes jurídicos, esto es, intereses individuales o colectivos, considerados indispensables para el entendimiento social ${ }^{73}$.

El principio de lesividad en la sodomía se complejiza en el contexto del siglo XIX por diversos factores. En primer lugar, debido a su origen proveniente de la tradición judeocristiana. En segundo lugar, la legislación penal y procesal penal chilena contaba con rasgos liberales y con resabios del Ancién Régime. En tercer lugar, se suma el repudio (legal y moral) por parte de dos instituciones: el Estado liberal chileno y la Iglesia católica. Finalmente, será el Estado chileno, a través del Poder Judicial y específicamente por medio de los juzgados del crimen y las cortes de apelaciones, quien condenará o absolverá a algún individuo acusado de sodomía.

El primer bien jurídico a proteger frente a las prácticas sodomíticas correspondía a la familia, que es la primera institución en que el individuo se puede desenvolver en sociedad. En la época estudiada, se consideraba que el delito de sodomía dañaba el orden social y la institución familiar porque impedía su reproducción. Según los discursos (religiosos y jurídicos) imperantes en la época, las prácticas sodomíticas impedían el desarrollo de la familia nuclear.

El segundo bien jurídico a proteger correspondía a la moralidad pública, según la cual se determinaban los vicios e inmoralidades que en un determinado tiempo histórico se consideraban importantes de sancionar para mantener el correcto funcionamiento de la estructura social. Desde el discurso, la moralidad pública de aquel entonces repudiaba las prácticas sexuales que no estuvieran al interior del matrimonio. Por consiguiente, en el Chile decimonónico, la sodomía fue calificada como un vicio y una transgresión a los cánones de la época.

\section{El delito de sodomía en los comentaristas del Código Penal}

Después de la entrada en vigencia del Código Penal el 1 de marzo de 1875, fueron publicados tres comentarios sobre este texto que describían, analizaban y comparaban, artículo por artículo, las leyes chilenas con la legislación internacional. En estas publicaciones los penalistas chilenos señalaron sus consideraciones sobre el delito de sodomía.

Los comentaristas del texto penal fueron seguidores del liberalismo penal (teoría neoclásica), por lo tanto, sus trabajos se inspiraron en las ideas de los penalistas

\footnotetext{
${ }^{71}$ Ibíd.

${ }^{72}$ Ferrajoli, Luigi, El principio de lesividad como garantía penal, en Revista Nuevo Foro Penal, 8/79 (2012), pp. 100-114.

${ }^{73}$ Politoff, Sergio; Matus, Jean Pierre; Ramírez, María, cit. (n. 8), p. 67.
} 
europeos de dicha tendencia, entre los cuales se destacaban: Pellegrino Rossi, Joaquín Francisco Pacheco, Francesco Carrara (1805-1888), Gaetano Filageri (1753-1788), Adolphe Chauveau (1802-1868), Carl Joseph Anton Mittermaier (1787-1867), Faustin Hélie (1799-1884) y Paul Johann Ritter Von Feuerbach $(1775-1833)^{74}$.

Alejandro Fuenzalida (1839-1890) fue un jurista chileno que publicó en tres tomos en el año 1883, el Código Penal comentado i explicado. Su labor se desarrolló fundamentalmente en el Poder Judicial, siendo juez en Antofagasta, juez de letras en lo criminal de Lima (capital del Perú) desde el 5 de abril de 1883, en nombre de la ocupación chilena y finalmente ministro de la Corte de Apelaciones de Iquique desde el 24 de noviembre de 1884, falleciendo en el ejercicio del cargo ${ }^{75}$. Fuenzalida, a pesar de asumir las ideas liberales de los tratadistas extranjeros en algunas temáticas, cuando analizó la sodomía continuó empleando una argumentación ligada al Ancién Régime: "La sodomía y la bestialidad eran grandes crímenes en las legislaciones antiguas: la ley $1^{\text {a }}$ tít. $3^{\text {o }}$ libro 12 de la Novísima Recopilación imponía la pena del fuego, lo mismo que la legislación romana. Más, muchos códigos modernos han borrado estas acciones del catálogo de los crímenes considerando que, por más abominables que sean, no reúnen los requisitos necesarios"76.

Fuenzalida caracteriza el delito de sodomía desde la antropología cristiana calificándolo como un acto horrendo para la moral y las costumbres justificando sus planteamientos a través de la legislación del Ancién Régime (Novísima Recopilación de 1805) o del imperio romano ${ }^{77}$. Para el penalista la sodomía era un hecho repulsivo, sin embargo, estaba de acuerdo con la supresión de este delito, su fundamentación radicó en una consideración de la técnica penal, este no reunía las condiciones para ser calificado un ilícito.

El penalista analizó la ambigüedad del código respecto al delito y su dificultad de aplicación: 'Ya que el código conservó la antigua doctrina al menos debió imponer una pena de más grados para que los tribunales pudiesen proporcionarla a la diversa gravedad de los hechos"78. Según el jurista la sodomía no cuenta con una gradación penal para sancionar a los acusados de acuerdo al criterio legal de faltas, cuasidelitos y delitos para así poder evaluar las diversas aristas del ilícito.

En líneas posteriores Fuenzalida planteaba: "Estos gravísimos pecados, en efecto, se verifican privadamente, sin escándalo de terceros, sin violación de un derecho, sin alarma ni daño social punible; y para perseguirlos es menester pene-

${ }^{74}$ Tomás y Valiente, Francisco, Manual de historia del derecho español (Madrid, Editorial Tecnos, 1987), pp. 493-506.

${ }^{75}$ Bravo LiRa, Bernardino, cit. (n. 24), II, p. 664.

${ }^{76}$ Fuensalida, Alejandro, cit. (n. 17), I, pp. 40-41.

${ }^{77}$ El emperador romano Constantino el Grande (326-337) promulgó la primera constitución explícita en contra de las relaciones sexuales entre varones: "donde el sexo pierde su sitio natural, donde existe el delito cuyo conocimiento no es decente, alli es donde las leyes se deben armar de la espada vengadorarico, BARCELÓ, to Núñez editor, pp. 664-665 e pasa al independentismo ovienen de la teolog", en DEMERS, Robert, De la lex scantinia aux récents amendements du Code criminel : homosexualité et droit dans une perspective historique, en Les Cabiers de droit, 25/4 (1984), pp. 779-780.

${ }^{78}$ Fuensalida, Alejandro, cit. (n. 17), I, pp. 42-43. 
trar en la vida íntima de las personas y descorrer el velo que cubre estas miserias humanas, causando escándalo, alarma y un daño verdadero"79.

El autor señalaba que la sodomía era un pecado y existía una gran dificultad para perseguir a los imputados de esa trasgresión porque esta se realizaba en espacios de intimidad. El jurista planteaba que perseguir las prácticas sodomíticas era un problema porque estas se desarrollaban en la esfera privada y su persecución colisionaría con el respeto al espacio privado de los ciudadanos.

El segundo jurista que se dedicó a analizar el código penal chileno fue Robustiano Vera (1844-1916), quien en 1883 publicó su tratado. Vera obtuvo su título de abogado en 1868 y fue secretario de la comisión redactora del Código Penal en 1872. A partir de 1876 comenzó a ejercer en Santiago, el cargo de promotor fiscal en lo criminal ${ }^{80}$. El texto de Vera a pesar de su clara influencia liberal, cuando analizó a la sodomía sus argumentos no se diferencian demasiados de las leyes alfonsinas que rigieron durante el periodo colonial: “¿Qué es sodomía? Es el concúbito entre personas de un mismo sexo o en vaso indebido. Llamase así porque deriva su nombre de la ciudad de Sodoma que, según la Historia Sagrada, fue castigada por el cielo con un incendio milagroso por haberse abandonado sus habitantes a tan vergonzoso vicio. Este delito se califica de público y se puede pesquisar de oficio. Este es un vicio tan perverso que trae una inerte prematura, arruina la inteligencia y degrada en extremo a la persona que se apodera de él, por eso conviene que la pena sea un tanto severa para combatirlo donde quiera que se presente y librar a la sociedad de esta plaga maldita por Dios"81.

En la primera línea, el autor indica una interpretación de Santo Tomás de Aquino que aparece en su obra la Summa Teológica y la cual es: el acto sexual a través del vaso indebido impide la reproducción natural y es una ofensa hacia Dios. El comentarista, sostiene una definición de la sodomía cercana a la de Aquino: "Cuando no se observa el modo natural de realizar el coito, sea porque se hace con un instrumento no debido" ${ }^{2}$. Agregando a lo anterior, la sodomía era considerada un coito a través de los vasos incorrectos, siendo reprobada por la Iglesia católica y el derecho penal porque impide la reproducción de la especie humana al interior de la familia cristiana.

Según Vera este delito corresponde a la esfera pública porque se permite pesquisarlo por oficio. Esto significa que el Estado puede perseguir a los acusados de prácticas sodomíticas a través de los fiscales, los jueces del crimen y los policías sin la necesidad de una denuncia de las partes involucradas, lo cual permitía una mayor facilidad para imputar a los sujetos.

Para el autor los acusados por el artículo 365 realizaban tres formas de ofensas. En primer lugar, un daño a Dios pues el coito entre varones transgredía el orden

\footnotetext{
${ }^{79}$ Ibíd., I, p. 42.

${ }^{80}$ Matus, Jean Pierre, Fernández, Fuenzalida y Vera: comentaristas, autodidactas y olvidados. Análisis diacrónico y sincrónico de la doctrina penal chilena del siglo XIX, en Revista Ius et Praxis, 12/1 (2006), p. 31.

${ }^{81}$ Vera, Robustiano, Código Penal de la República de Chile (Santiago de Chile, Imprenta de P. Cadot i ca., 1883), p. 564.

${ }^{82}$ De Aquino, Santo Tomás, cit. (n. 2), cuestión 154, Las especies de la lujuria, pp. 483-484.
} 
natural provocando una ruptura del pacto cristiano de la procreación y el amor al Señor tal como se indicaba en la Biblia. En segundo lugar, un menoscabo al orden social del país y a la familia que constituían las bases de la sociedad y en tercer lugar, un daño moral al sujeto ya que este se transforma en un perverso sexual, perdiendo su inteligencia y cayendo en una degradación moral que lo iguala con los vagabundos y los delincuentes ${ }^{83}$.

En la doctrina neoclásica la responsabilidad del delito sodomía sólo recaen en el individuo acusado por el tribunal. La sanción penal al sodomita no traerá la confiscación de sus bienes y a los de su familia como sucedía en la anterior legislación colonial. La pena del derecho penal chileno (tres años y un día) a las prácticas sodomíticas es un ejemplo que se castiga un pecado y un delito, pero a través de las técnicas jurídicas propias de la doctrina neoclásica.

El último comentarista al que nos referiremos es Pedro Javier Fernández. Nació en 1849 en Santiago y juró como abogado el 11 de enero de 1870. Salvo su actividad de diputado suplente representando al Partido Conservador por San Carlos en 1885-1891, Fernández ejerció toda su vida de jurista publicando sus comentarios del Código Penal de 1874 en una primera edición en 1877 y posteriormente una segunda edición entre $1889-1900^{84}$.

El penalista realizó un análisis con un énfasis descriptivo a diferencia de los estudios de Fuenzalida y Vera. El autor señaló lo ya expuesto en las discusiones de la Comisión Redactora del Código Penal (1870-1873) y además complementó al indicar que los delitos sexuales fueron considerados por los comisionados con una lógica concatenada: abuso deshonesto, sodomía, violación y corrupción de menores.

Según Fernández: "La sodomía no está penada especialmente por el código español, tampoco lo está en el belga ni en varios otros códigos extranjeros; pero si lo está en el código austriaco, artículo 113, designándolo como delito contra la naturaleza" ${ }^{85}$. Aunque el jurista citó una legislación europea que sancionaba a la sodomía en aquel tiempo, esa normativa nunca fue señalada como una de las fuentes empleadas durante el proceso de redacción del texto penal chileno.

\section{Conclusiones}

En este artículo se ha analizado el pecado-delito de sodomía a través de las legislaciones penales vigentes en Chile durante el siglo XIX. En el país, durante la época colonial (1541-1817) y parte del periodo republicano (1817-1875) se utilizó la legislación penal de la Monarquía Hispánica, cuyos presupuestos teóricos se encontraban fundamentados en la antropología cristiana. Las condenas estipuladas en dichas legislaciones en contra de los imputados por el delito de

\footnotetext{
${ }^{83}$ Vera, Robustiano, cit. (n. 81), p. 565.

${ }^{84}$ Matus, Jean Pierre, cit. (n. 80), p. 32.

${ }^{85}$ Fernández, Pedro Javier, Código Penal de la República de Chile, esplicado i concordado ( $2^{a}$ ed. notablemente aumentada i correjida, Santiago de Chile, Imprenta, Litografía i Encuadernación Barcelona, 1900), II, pp. 103-104.
} 
sodomía eran muy duras y suponían la hoguera, el exilio y/o la confiscación de los bienes para los responsables.

Posteriormente, la codificación del derecho penal en 1874 conservó el delito de sodomía, pero las penas fueron suavizadas (encarcelamiento por tres años). Por consiguiente, este estudio concluye que, a pesar de la transformación de la legislación penal, existió una permanencia en la larga duración histórica en el castigo de la sodomía en el territorio chileno, primero por parte del Imperio español y posteriormente en el Estado republicano.

En el Chile del siglo XIX no existía inconveniente para la cohabitación de elementos aparentemente contradictorios entre sí, como, por ejemplo, ser un liberal a ultranza en el plano económico y un conservador en el terreno político, cultural y social. Por esta razón, en el texto penal chileno, el castigo a la sodomía se fundamenta desde la moral cristiana y una formalización jurídica liberal. Las condenas carcelarias eran moderadas a través de un enunciado escueto y los acusados tenían algunas garantías en el procesamiento penal.

El pacto entre el Estado liberal y la Iglesia católica se representó de forma gráfica en el Código Penal de 1874. Por un lado, el texto imita las más modernas legislaciones de Europa (España, Bélgica y Francia) y contiene una serie de formalidades liberales, como la igualdad ante la ley, el debido proceso, garantías procesales, etc. Sin embargo, por otro lado, conserva los valores morales cristianos sobre la sexualidad, rechazando las prácticas sexuales entre dos varones independientemente de su edad y el consentimiento entre ellos.

A través del análisis del delito de sodomía, este estudio revela los espacios grises del Estado liberal chileno y su carácter elitista, censitario y jerárquico. A la vez, señala las fábulas y los relatos fundacionales de dicho Estado que se desmienten en sus prácticas, como sucede con la redacción del texto penal nacional. El aporte de esta investigación sobre el delito de sodomía ha consistido en develar una de las tantas aristas del liberalismo chileno. Se ha analizado la pervivencia de un pecado en la legislación penal en Chile desde la colonización española hasta la instauración de la República, lo que configura que en la práctica no existen regímenes políticos puros, sino que siempre hay una mixtura que en este caso se evidencia en la influencia ejercida por el liberalismo y el catolicismo.

\section{BiBLIOGRAFÍA}

Actas de las sesiones de la Comisión Redactora del Código Penal Chileno (Santiago, Imprenta de la República de Jacinto Núñez, 1873).

AnguITA, Ricardo, Leyes promulgadas en Chile: desde 1810 hasta el 1 de junio de 1913

(Santiago, Imprenta Litografía i Encuadernación Barcelona, 1913).

ANSALDI, Waldo, Frivola y casquivana, mano de hierro en guante de seda. Una propues-

ta para conceptualizar el término oligarquía en América Latina, en Cuadernos del CLAEH, 61 (1992), pp. 43-48.

ARranz, Luis, Liberalismo, democracia y revolución en Europa (1830-1939). Los casos de Francia, Italia, Alemania y Reino Unido, en García, Marcela; DEL Rey, Fernando, Los desafios de la libertad. Transformación y crisis del liberalismo en Europa y América Latina (Madrid, Biblioteca Nueva, 2008), pp. 23-63. 
Alfonso el Sabio x, Las Siete Partidas (Madrid, Imprenta Real, 1807), III, Partida Séptima, Título XXI, pp. 664-665.

AwI, Alexandre, ¿Qué dice la Biblia sobre la homosexualidad? en Teología y Vida 42/4 (2001), pp. 377-398.

Boswell, John, Cristianismo, tolerancia social y homosexualidad (Barcelona, Munchnik Editores S.A., 1992).

Bravo Lira, Bernardino, Anales de la judicatura chilena (Santiago, Andros Impresores, 2011), I-II.

Biblia de Jerusalén (Bilbao, Desclee de Brower, 1987).

Carlos IV, Novísima Recopilación de las leyes de España (Impresa en Madrid 1805), V, Libro XII, De los delitos, y sus penas: y de los juicios criminales. Título XXX, De la sodomía, y bestialidad, pp. 427-429.

Campos Harriet, Fernando, Historia constitucional de Chile (Santiago, Editorial Jurídica de Chile, 2005).

Código Penal de Francia de 1791, en Revista de Derecho Penal y Criminología, Tercera época, 1 (2009), pp. 481-517.

Código Penal de la República de Chile (Santiago de Chile, Imprenta de la República, Jacinto Núñez Editor, 1874).

Código Penal de España (ed. reformada, Madrid, Imprenta Nacional, 1850).

Corral Talcini, Hernán, La privatización de la sexualidad y de la familia, en Simposio Internacional: Revisión del legado jurídico de la Revolución francesa en las Américas 28 de abril 2011 (Santiago, Universidad Bernardo O'Higgins, 2011), pp. 147-152.

Collier, Simon; Sater, William, Historia de Chile 1808-1994 (Madrid, Cambridge University Press, 1999).

CHARTIER, Roger, Espacio público, crítica y desmoralización en el siglo XVIII. Los orígenes culturales de la Revolución Francesa (Barcelona, Gedisa, 1995).

Constitución de la República de Chile jurada y promulgada el 25 de mayo de 1833 (Santiago, Imprenta La Opinión, 1833).

Constitución Política de la República de Chile promulgada el 18 de septiembre de 1925 (Santiago, Imprenta Universitaria, 1925).

Cury, Enrique, Derecho penal Parte general (Santiago, Editorial Jurídica de Chile, 1982), II.

Damien, André, Code pénal, en Tulard, Jean, Dictionnaire Napoléon (Paris, Fayard, 1987), pp. 433-435.

De Aquino, Santo Tomás, Summa Teologica (Madrid, Biblioteca de Autores Cristianos, 1944).

De Rivacoba, Manuel, Evolución histórica del derecho penal chileno (Valparaíso, Edeval, 1999).

Del Villar Brito, Waldo, Cien años de legislación penal codificada de Chile, en DE Rivacoba, Manuel, Actas de las jornadas internacionales de derecho penal en celebración del centenario del Código penal chileno (Valparaíso, Edeval, 1975), pp. 361-365.

Demers, Robert, De la lex scantinia aux récents amendements du Code criminel: homosexualité et droit dans une perspective historique, en Les Cahiers de Droit, 25/4 (1984), pp. 777-800.

Deschner, Karheinz, Historia sexual del cristianismo (Zaragoza, Editorial Yalde, 1993).

Encina, Francisco Antonio, Historia de Chile (Santiago, Editorial Lord Cochrane, 1983), XXXIX. 
ERrázuriz, Federico, Discurso de su excelencia el Presidente de la República en la apertura del Congreso Nacional de 1874 (Santiago de Chile, Imprenta Nacional, 1874).

Errázuriz, Federico; Barceló, José María, Mensaje del Gobierno acompañando el presente código penal al Congreso, 27 de octubre de 1873, en Código Penal (Santiago, Editorial Jurídica de Chile, 1984), pp. 13-18.

ETCHEPARE, Jaime, Surgimiento y evolución de los partidos políticos en Chile 1857-2003 (Concepción, Universidad Católica de la Santísima Concepción, 2006).

Etcheberry, Alfredo, Derecho Penal, Parte general ( $3^{\text {a }}$ ed. revisada y actualizada, Santiago, Editorial Jurídica de Chile, 1997), I.

Eyzaguirre, Jaime, Historia de las instituciones politicas y sociales de Chile (Santiago, Editorial Universitaria, 1982).

-Historia del derecho (Santiago, Editorial Universitaria, 2004).

Fabres, José Clemente, Los cementerios católicos, en El Estandarte Católico No 2.878, Santiago de Chile, 16 de diciembre de 1883.

Fernández, Pedro Javier, Código Penal de la República de Chile, esplicado i concordado ( $2^{a}$ ed. notablemente aumentada i correjida, Santiago de Chile, Imprenta, Litografía i Encuadernación Barcelona, 1900), II.

Ferrajoli, Luigi, El principio de lesividad como garantía penal, en Revista Nuevo Foro Penal, 8/79 (2012), pp. 100-114.

- El paradigma garantista. Filosofía crítica del derecho penal (Madrid, Editorial Trotta, 2018).

Fuensalida, Alejandro, Concordancia i comentario del Código Penal chileno (Lima, Imprenta Comercial, 1883), I.

Foucault, Michel, Vigilar y castigar. Nacimiento de la prisión (México, Siglo XXI Editores, 1999).

—QQué es la Ilustración?, en Daimon Revista Internacional de Filosofia, 7 (1993), pp. 5-14.

GonZÁlez, Carolina, Hombres de verdad, maricones y sodomitas Aproximaciones a la mantención del orden heterosexual: homofobia y construcción de masculinidad Chile fines del S. XIX, en Conservadurismo y transgresión en Chile: reflexiones sobre el mundo privado (Chile, Lom Ediciones, 2005), pp. 231-268.

Golinsky, J.V., Science in the Enlightenment, en History Science, 24 (1986), pp. 411-424.

GuZMÁn, José Luis, Reseña histórica de la codificación y procesal penal en Chile, en La ciencia penal en la Universidad de Chile, Facultad de Derecho, Universidad de Chile, Libro homenaje a los profesores del Departamento de Ciencias Penales (Santiago, Universidad de Chile, 2013), pp. 105-128.

HankIns, Thomas, Ciencia e ilustración (Madrid, Siglo XXI Editores, 1988).

HayeK, Friedrich, Liberalismo, en Revista Ciencia Politica, 4/2 (1982), pp. 122-145.

Hopman, Jan, La sodomía en la historia de la moral eclesial, en OlaVARRIA, José; PARRINI, Rodrigo, Masculinidades, identidad, sexualidad y familia, primer encuentro de estudio de la masculinidad (Nuñoa, Flacso, 2000), pp. 113-122.

IÑESTA, Emilia, Antecedentes históricos-jurídicos del código penal chileno de 1874, en DE La Puente Brunke, José; Guevara Gil, Jorge Armando, XIV congreso del Instituto Internacional de Historia del Derecho Indiano, Derecho, instituciones y procesos históricos (Perú, Instituto Riva- Agüero de la Pontificia Universidad Católica del Perú, 2008), III, pp. 203-242.

-El Código Penal chileno de 1874, en Revista Chilena de Historia del Derecho, 19 (2003-2004), pp. 293-328. 
Jofré, Luis, Don Eulogio Altamirano, en Revista Chilena de Historia y Geografía, 68 (1930), pp. 73-76.

Kant, Immanuel, ¿Qué es la Ilustración?, en Filosofia de la historia (México, Fondo de la Cultura Económica, 1994).

Krebs, Ricardo; Muñoz, María Angélica; Valdivieso, Patricio, Historia de la Pontificia Universidad Católica de Chile, 1888-1988 (Santiago, Ediciones de la Universidad Católica de Chile, 1994).

Matteucci, Nicola, Liberalismo, en Bobbio, Norberto; Matteucci, Nicola, Diccionario de politica, (México, Siglo XXI Editores, 1982), pp. 905-931.

Matus, Jean Pierre; Politoff, Sergio; Ramírez, Cecilia, Lecciones de derecho penal chileno. Parte general (Santiago, Editorial Jurídica de Chile, 2004).

MAtus, Jean Pierre, Fernández, Fuenzalida y Vera: comentaristas, autodidactas y olvidados. Análisis diacrónico y sincrónico de la doctrina penal chilena del siglo XIX, en Revista Ius et Praxis, 12/1 (2006), pp. 31-67.

—La doctrina penal de la (fallida) recodificación chilena del Siglo XX y principios del XXI, en Política Criminal, 5/9 (Julio 2010), Art. 4, pp. 143-206, en http://www. politicacriminal.cl/Vol_05/n_09/Vol5N9A4.pdf [visitado el 05-03.2018).

- Legislación penal vigente en Chile (Santiago, Legal Publishing Chile-Thomson Reuters, 2012).

Matus, Jean Pierre; Ramírez, Cecilia, Manual de derecho penal chileno parte especial (Valencia, Tirant lo Blanch, 2018).

Martinic, Zvonimir, Relaciones Iglesia-Estado en Chile, desde 1820 hasta la muerte del arzobispo Valentín Valdivieso, en 1878, en Revista Archivum, Valparaíso, 3 (s/f), pp. 21-28.

MARTín, María, Aproximación histórica al tratamiento jurídico y social dado a la homosexualidad en Europa, en Estudios Constitucionales, 9/1(2011), pp. 245-276.

Martínez, Rosa María, La Iglesia católica en la América independiente (siglo XIX) (Madrid, Editorial MAPFRE, 1992).

Munck, Thomas, Historia social de la Ilustración (Barcelona, Editorial Crítica, 2001).

NovoA, Eduardo, Curso de derecho penal chileno (Santiago, Editorial Jurídica EdiarConosur, 1985), I.

PASTORELlo, Thierry, L'abolition du crime de sodomie en 1791: un long processus social, répressifet pénal, en Cahiers d'Histoire. Revue d'Histoire Critique, 112-113 (2010), pp. 197-208.

PeÑA, Silvia, Las raices histórico-culturales del derecho penal chileno, en Revista de Estudios Histórico-Jurídicos, 7 (1982), pp. 89-314.

Quintano, Antonio, La influencia del derecho penal español en las legislaciones hispanoamericanas (Madrid, Ediciones Cultura Hispánica, 1953).

Revenin, Régis, Homosexualité et prostitution masculines á Paris 1870-1918 (Paris, L'Harmattan, 2005).

Rodríguez, Luis, Delitos sexuales de conformidad con las modificaciones introducida por la ley No19.617 de 1999 (Santiago, Editorial Jurídica de Chile, 2000).

Rojas Araya, Joel, El castigo de la sodomía y la libertad sexual en Chile, en Anuario de la Facultad de Ciencias Jurídicas, Sección I (2001), pp. 151-169.

RojAs, Ximena, Don Adolfo Ibáñez. Su gestión con el Perú y Bolivia 1870-1879 (Santiago, Editorial Andrés Bello, 1970).

SÁnCHEZ, Gonzalo, Manuel José Yrarrázaval Larraín una vida entregada a la patria (Santiago, Ediciones Pontificia Universidad Católica de Chile, 2005). 
Stuven, Ana María, La Iglesia católica chilena en el siglo XIX. Encuentros y desencuentros con la modernidad filosófica, en Teología y Vida, 56/2 (2015), pp. 187-217.

Tomás y Valiente, Francisco, Manual de historia del derecho español (Madrid, Editorial Tecnos, 1987).

Vera, Robustiano, Código Penal de la República de Chile (Santiago de Chile, Imprenta de P. Cadot i ca., 1883).

VeILlon, Didier, La rédaction du Code pénal de 1810, en Slovenian Law Review, 6/1-2, (december 2009), pp. 143-157. 